\title{
Quatorze anos de desigualdade: Mulheres na carreira acadêmica de Filosofia no Brasil entre 2004 e 2017
}

\author{
Fourteen years of inequality: Women in the Philosophy academic \\ career in Brazil between 2004 and 2017
}

\author{
Carolina Araújo \\ correio.carolina.araujo@gmail.com \\ (Universidade Federal do Rio de Janeiro, Rio de Janeiro, Brasil)
}

\begin{abstract}
Resumo: Este estudo analisa os números de discentes e docentes na Graduação e PósGraduação em Filosofia no Brasil a partir dos dados oficiais do INEP e da CAPES de 2004 a 2017. As mulheres são, em média, $36,44 \%$ dos graduandos, 30,6\% dos mestrandos, $26,98 \%$ dos doutorandos e $20,14 \%$ dos docentes de pós-graduação. Ele mostra que, na carreira acadêmica, as chances do profissional do sexo masculino são, em média, 2,3 vezes maiores do que as do profissional de sexo feminino. Ademais, indica que há uma tendência aumento da desigualdade ao longo dos últimos 14 anos.
\end{abstract}

Palavras-chave: mulheres; filosofia; Brasil; carreira acadêmica; gênero.

\begin{abstract}
This study analyzes the figures for students and professors in Undergraduate and Graduate Programs in Philosophy in Brazil based on the official data of INEP and CAPES from 2004 to 2017. Women are on average $36.44 \%$ of the undergraduate students, $30.6 \%$ of the MA students, $26.98 \%$ of the Ph.D students and $20.14 \%$ of the professors in Graduate Programs. It shows that, in the academic career, the chances of the male professional are on average 2.3 times higher than those of the female professional. In addition to this average, it indicates a trend towards increasing inequality over the course of the last 14 years.
\end{abstract}

Keywords: women; philosophy; Brazil; academic career; gender

\section{Introdução: ${ }^{1}$}

A qualquer um que frequente a área é evidente a desigualdade numérica entre homens e mulheres trabalhando com Filosofia em contextos acadêmicos. Uma primeira tentativa de mapear o problema no Brasil (Araújo, 2016) mostrou um retrato do ano de 2015 em que as mulheres discentes na Pós-Graduação totalizavam 27\% e as docentes $21 \%$. A carreira em filosofia é eminentemente acadêmica, de modo que, à medida que não há cargo mais alto e valorizado para o filósofo além do docente de

\footnotetext{
1 Este trabalho não seria possível sem a preciosa contribuição do Vinícius Berlendis de Figueiredo, coordenador da área de Filosofia junto à Capes de 2014 e 2018, e Lívia Amaral Schumann, analista em Ciência e Tecnologia da Divisão de Avaliação da Capes, a quem gostaria de agradecer mais uma vez.
} 
pós-graduação, esses números retratam também os padrões de sucesso profissional na área. Em contraste com uma média de 38\% de concluintes na graduação em 2014, o relatório de Araújo (2016) apontava a grande desigualdade na presença de homens e mulheres indicando que as mulheres tinham 2,5 vezes menos oportunidades de chegar ao cargo mais alto do que seus colegas homens. Três problemas de método podem ser atribuídos ao referido relatório: (i) o fato de não distinguir entre cursos de mestrado e doutorado; (ii) o fato de comparar diferentes etapas da carreira em um mesmo ano e (iii) o fato de não concluir qualquer tendência histórica sobre o problema. 0 presente trabalho pretende suprir em certa medida essas lacunas.

\section{Metodologia}

Esse trabalho consiste no levantamento de números a partir de duas fontes gerais, ambas documentos públicos oficiais disponibilizados nos sítios oficiais dos órgãos públicos: os dados dos cursos de graduação de filosofia extraídos pelo Instituto Nacional de Estudos e Pesquisas Educacionais Anísio Teixeira (INEP) na ocasião da realização do Exame Nacional de Cursos (ENADE) e as tabelas produzidas pelo sistema de avaliação de Programas de Pós-Graduação da Coordenação de Aperfeiçoamento de Pessoal de Nível Superior (CAPES). Os dados do INEP trazem quantitativos por categorias: ingressantes e concluintes (2005 e 2008), licenciatura e bacharelado (2011, 2014 e 2017), cursos presenciais e à distância (2017). Com exceção dos ingressantes e concluintes, que vêm aqui distintos, os números das demais categorias foram todos somados e a proporção de mulheres contabilizada. Assim, os números que constam aqui não necessariamente estão publicados nos relatórios do INEP, mas foram calculados a partir dos dados ali presentes. Algo semelhante ocorre com as tabelas da CAPES, que trazem apenas quantitativos brutos por Programa de PósGraduação (daqui em diante PPG) por ano: procedeu-se ao cálculo dos dados abaixo apresentados.

Em relação aos dados da CAPES, os dados se referem ao sexo indicado para cada indivíduo cadastrado no sistema. Em alguns casos, o sexo não foi indicado e, nesses, considerou-se a indicação “feminino" por oposição à soma "masculino" e "não cadastrado". Só foram considerados os números de discentes na categoria "matriculado" e de docentes na categoria "permanente". Porque se objetiva descrever a carreira acadêmica em filosofia, descartou-se os números dos discentes matriculados em Mestrados Profissionais, embora tenham sido considerados os números dos docentes desses PPGs. Com a exceção dos números nacionais, a unidade de análise dos dados da pós-graduação é sempre o PPG, tomado a cada ano segundo a porcentagem de indivíduos do sexo feminino a ele vinculados. Há PPGs que só oferecem o curso de mestrado, um que só oferece o doutorado, além 
de outros que oferecem ambos os cursos. Há PPGs que foram fechados ao longo dos 14 anos, outros que foram abertos, inclusive bem recentemente abertos. Todos eles foram considerados e suas médias foram calculadas por ano de funcionamento. A identificação dos PPGs se faz segundo as seguintes siglas:

\begin{tabular}{|c|c|}
\hline \multicolumn{2}{|r|}{ Tabela1: Siglas dos PPGs } \\
\hline CEFET/RJ & Centro Federal de Educação Tecn. Celso Suckow da Fonseca \\
\hline FAJE & Faculdade Jesuíta de Filosofia e Teologia \\
\hline FSB & Faculdade São Bento \\
\hline FUFPI & Fundação Universidade Federal do Piauí \\
\hline FUFSE & Fundação Universidade Federal de Sergipe \\
\hline PUC-RIO & Pontifícia Universidade Católica do Rio de Janeiro \\
\hline PUC/PR & Pontifícia Universidade Católica do Paraná \\
\hline PUC/RS & Pontifícia Universidade Católica do Rio Grande do Sul \\
\hline $\mathrm{PUC} / \mathrm{SP}$ & Pontifícia Universidade Católica de São Paulo \\
\hline UCS & Universidade de Caxias do Sul \\
\hline UECE & Universidade Estadual do Ceará \\
\hline UEL & Universidade Estadual de Londrina \\
\hline UEM & Universidade Estadual de Maringá \\
\hline UERJ & Universidade do Estado do Rio de Janeiro \\
\hline UERN & Universidade do Estado do Rio Grande do Norte \\
\hline UFABC & Fundação Universidade Federal do ABC \\
\hline UFAM & Universidade Federal do Amazonas \\
\hline UFBA & Universidade Federal da Bahia \\
\hline UFC & Universidade Federal do Ceará \\
\hline UFCG & Universidade Federal de Campina Grande \\
\hline UFES & Universidade Federal do Espírito Santo \\
\hline UFF & Universidade Federal Fluminense \\
\hline UFG & Universidade Federal de Goiás \\
\hline UFJF & Universidade Federal de Juiz de Fora \\
\hline UFMA & Universidade Federal do Maranhão \\
\hline UFMG & Universidade Federal de Minas Gerais \\
\hline UFMS & Universidade Federal do Mato Grosso do Sul \\
\hline UFMT & Universidade Federal de Mato Grosso \\
\hline UFOP & Universidade Federal de Ouro Preto \\
\hline UFPA & Universidade Federal do Pará \\
\hline UFPB/J.P. & Universidade Federal da Paraíba/João Pessoa \\
\hline UFPE & Universidade Federal de Pernambuco \\
\hline $\begin{array}{l}\text { UFPE-UFPB - } \\
\text { UFRN }\end{array}$ & $\begin{array}{l}\text { Doutorado Interinstitucional entre Universidade Federal de Pernambuco; } \\
\text { Universidade Federal da Paraíba e Universidade Federal do Rio Grande do } \\
\text { Norte }\end{array}$ \\
\hline UFPEL & Universidade Federal de Pelotas \\
\hline UFPR & Universidade Federal do Paraná \\
\hline
\end{tabular}




\begin{tabular}{|l|l|}
\hline UFRGS & Universidade Federal do Rio Grande do Sul \\
\hline UFRJ/PPGF & Filosofia: Universidade Federal do Rio de Janeiro \\
\hline UFRJ/PPGLM & Lógica e Metafísica: Universidade Federal do Rio de Janeiro \\
\hline UFRN & Universidade Federal do Rio Grande do Norte \\
\hline UFRRJ & Universidade Federal Rural do Rio de Janeiro \\
\hline UFSC & Universidade Federal de Santa Catarina \\
\hline UFSCAR & Universidade Federal de São Carlos \\
\hline UFSM & Universidade Federal de Santa Maria \\
\hline UFT & Universidade Federal do Tocantins \\
\hline UFU & Universidade Federal de Uberlândia \\
\hline UGF & Universidade Gama Filho \\
\hline UNB & Filosofia: Universidade de Brasília \\
\hline UNB-M & Metafísica: Universidade de Brasília \\
\hline UNESP/MAR & Universidade Estadual Paulista Júlio de Mesquita Filho/Marilia \\
\hline UNESPAR & Universidade Estadual do Paraná \\
\hline UNICAMP & Universidade Estadual de Campinas \\
\hline UNIFESP & Universidade Federal de São Paulo \\
\hline UNIMONTES & Universidade Estadual de Montes Claros \\
\hline UNIOESTE & Universidade Estadual do Oeste do Paraná \\
\hline UNISINOS & Universidade do Vale do Rio dos Sinos \\
\hline USJT & Universidade São Judas Tadeu \\
\hline USP & Universidade de São Paulo \\
\hline
\end{tabular}

\section{Discentes de graduação}

Os dados dos cursos de graduação em filosofia, coletados a cada três anos por ocasião do ENADE, demonstram que desde o ingresso na graduação a Filosofia é uma carreira buscada majoritariamente por homens. Em 2005, o ENADE indicou que a média de mulheres ingressantes e concluintes seria de $34,1 \%$, com uma proporção feminina maior entre concluintes do que entre ingressantes. ${ }^{2}$ Se consideramos que o relatório indica um total de 3929 ingressantes, podemos contabilizar um número máximo de 1340 mulheres dentre eles. Em 2008, a maioria masculina era também marcada, computando 61,2\% dos 5439 ingressantes, ou seja, 2110 mulheres ingressaram no curso nesse ano (cf. INEP, 2008, p. 85). Infelizmente, a partir de 2011 o Inep passou a registrar apenas dados de concluintes. Devido à sua pequena amostragem, optamos por não trabalhar com a média de ingressantes, apenas com a de concluintes da graduação. Mesmo assim, os dados de 2005 e 2008 foram utilizados para elaborar a

2 A formulação do texto é lamentavelmente vaga quanto aos números: "Na área de Filosofia, $65,9 \%$ dos estudantes são do sexo masculino enquanto $34,1 \%$ são do sexo feminino. 0 número de ingressantes do sexo masculino é sutilmente superior à percentagem de concluintes do mesmo sexo. Em relação ao sexo feminino, ocorre o contrário: a percentagem de concluintes é superior à de ingressantes" (INEP, 2005, p. 95). 
progressão na carreira dos casos fictícios analisados adiante.

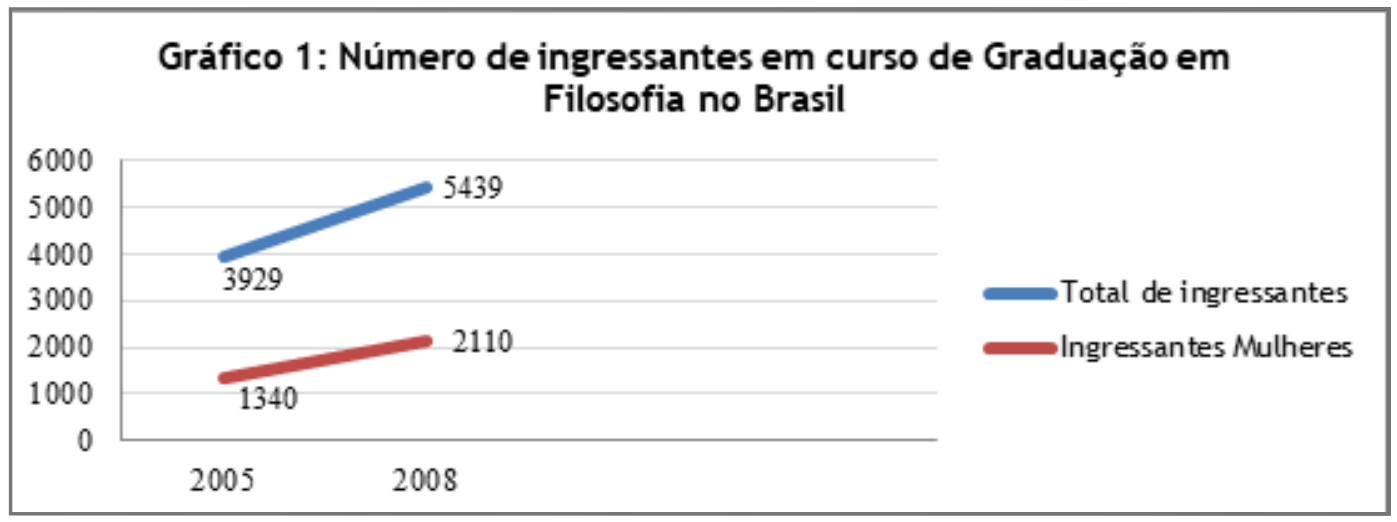

Os números dos concluintes da Graduação em Filosofia foram apurados pelo INEP em série contínua ao longo de 5 triênios. Neles se pode constatar a tendência de crescimento contínuo do total de estudantes e um aumento progressivo na proporção de mulheres concluintes.

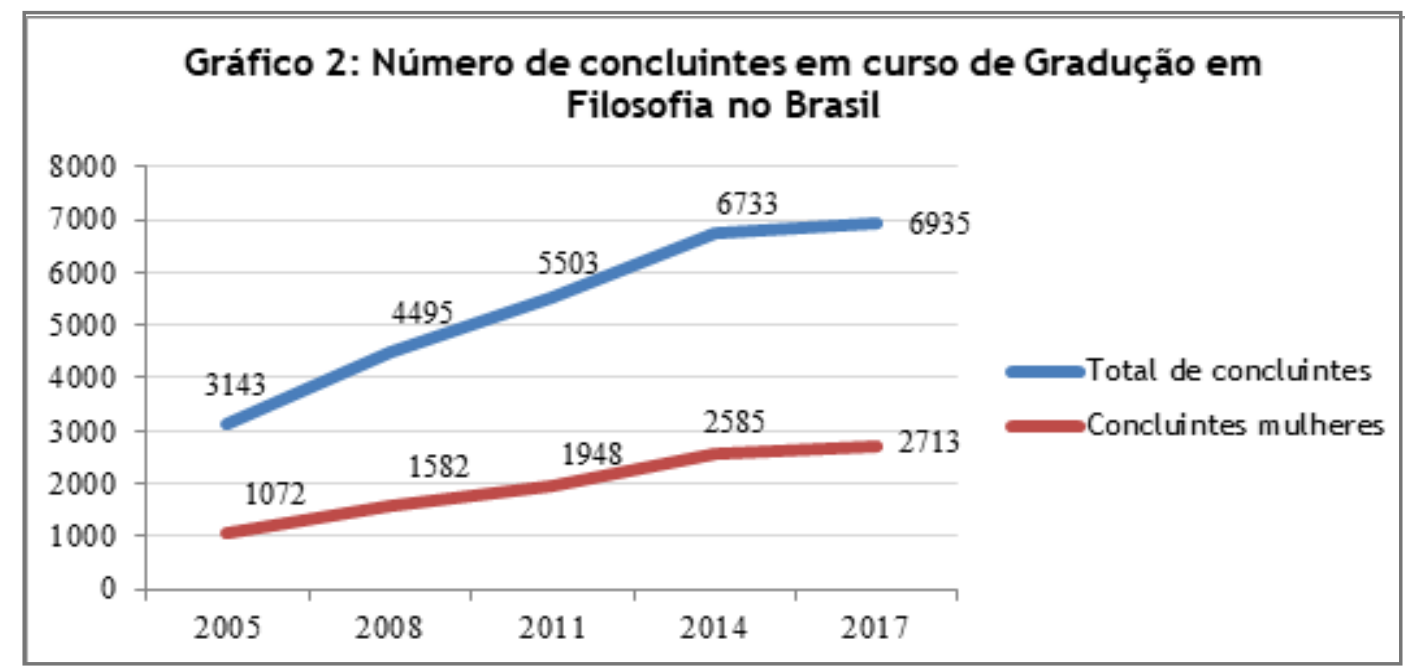

Se comparamos a proporção de mulheres na série histórica da graduação, verificamos o seguinte: há um aumento da proporção de mulheres ingressantes entre 2005 (34,1\%) e 2008 (38,8\%) (INEP, 2008, p. 85), porém, devido à vagueza do enunciado no relatório de 2005, não há tanto rigor nesse número. Quanto aos concluintes, partimos do vago número de 34,1\% de mulheres em 2005; em seguida temos que, em 2008, os homens eram 64,8\% dos concluintes (INEP, 2008, p. 85) e que, em 2011, esse número era de 64,6\% (INEP, 2011, p. 106-108). Em 2014, os dados foram separados entre os cursos de Bacharelado e Licenciatura. Nesse ano, em se calculando a média geral a partir dos dados do INEP, chegamos à porcentagem de $61,6 \%$ do sexo masculino e $38,4 \%$ do sexo feminino (INEP, 2014, p. 139). Finalmente, 
em 2017, os dados foram separados não apenas em Bacharelado e Licenciatura, mas também em cursos presenciais e à distância. O cálculo geral resulta em 39,12\% de mulheres dentre os concluintes. O notável, porém, no relatório de 2017 é que as mulheres são maioria nos cursos de Licenciatura à distância, 52\% (INEP, 2017, p. 49), mantendo a minoria nas outras três categorias. O fenômeno da Licenciatura à distância responde pelo aumento da proporção de mulheres no número geral de 2017. Verifica-se enfim, em todos os números, um aumento constante na proporção de mulheres ao longo dos anos, de 34,1\% em 2005 a 39,12\% em 2017. Se tomamos a média ao longo de todos os anos, temos $36,44 \%$ de discentes do sexo feminino concluindo a graduação.

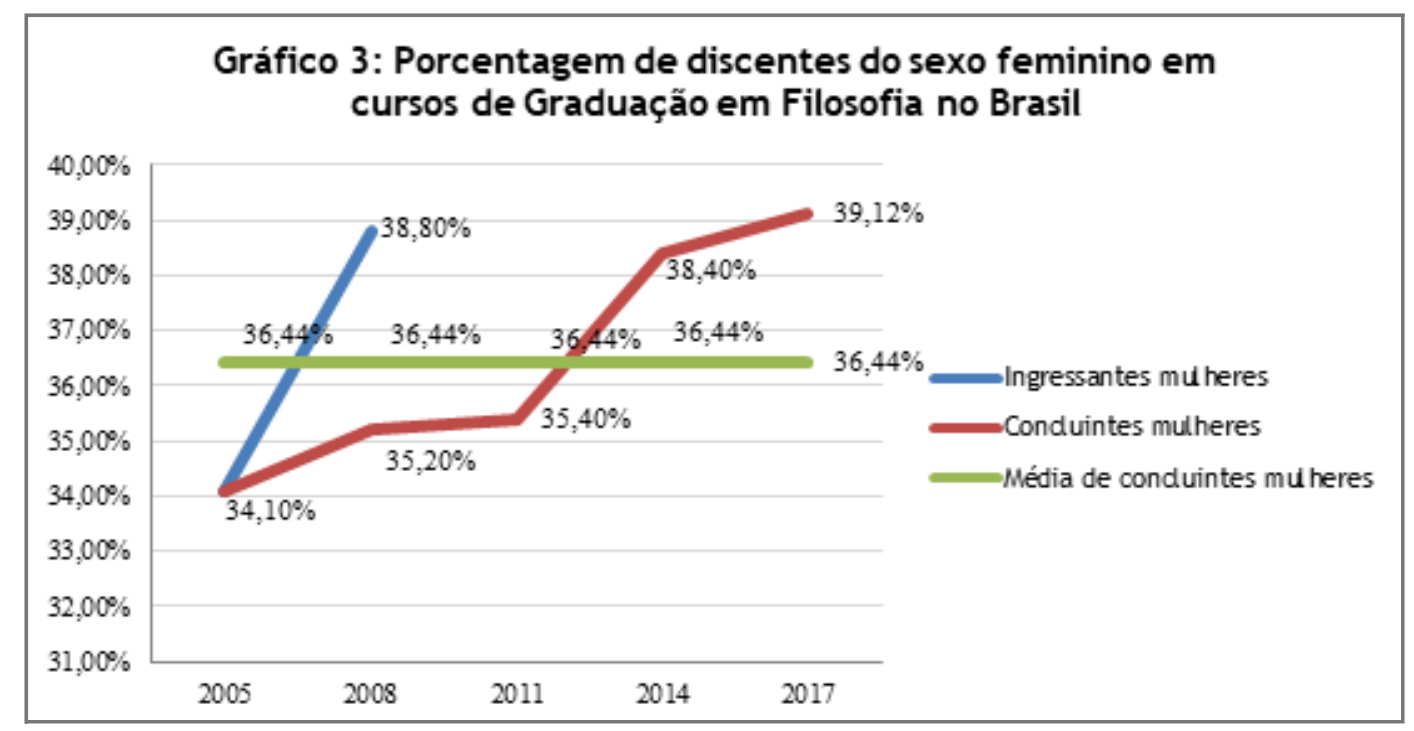

\section{Discentes de mestrado}

Os números de discentes no mestrado em Filosofia no Brasil têm um comportamento singular ao longo dos 14 anos pesquisados. Há uma tendência de crescimento no número de estudantes que é bruscamente interrompida entre 2012 e 2013 com uma queda de mais de $36 \%$, passando de 1965 para 1251 alunos matriculados. Chamarei esse fenômeno de “Evento 2013". A análise nominal detalhada indicou que boa parte dos concluintes de 2012 figuram na listagem de discentes de doutorado no ano seguinte, de modo que o Evento 2013 inclui também um significativo aumento das matrículas de doutorado em 2013 (ver adiante). A razão primordial do Evento 2013 é a queda no número de matrículas no mestrado neste ano. Esse fenômeno volta a se repetir em 2017, porém ali ele corresponde a uma queda, e não a um aumento, nas matrículas de doutorado. No Evento 2013, a queda no número de mulheres discentes guardou a mesma proporção do total de indivíduos, ou seja, tanto o número total de alunos, quanto o número de alunas caíram cerca de $36 \%$. 


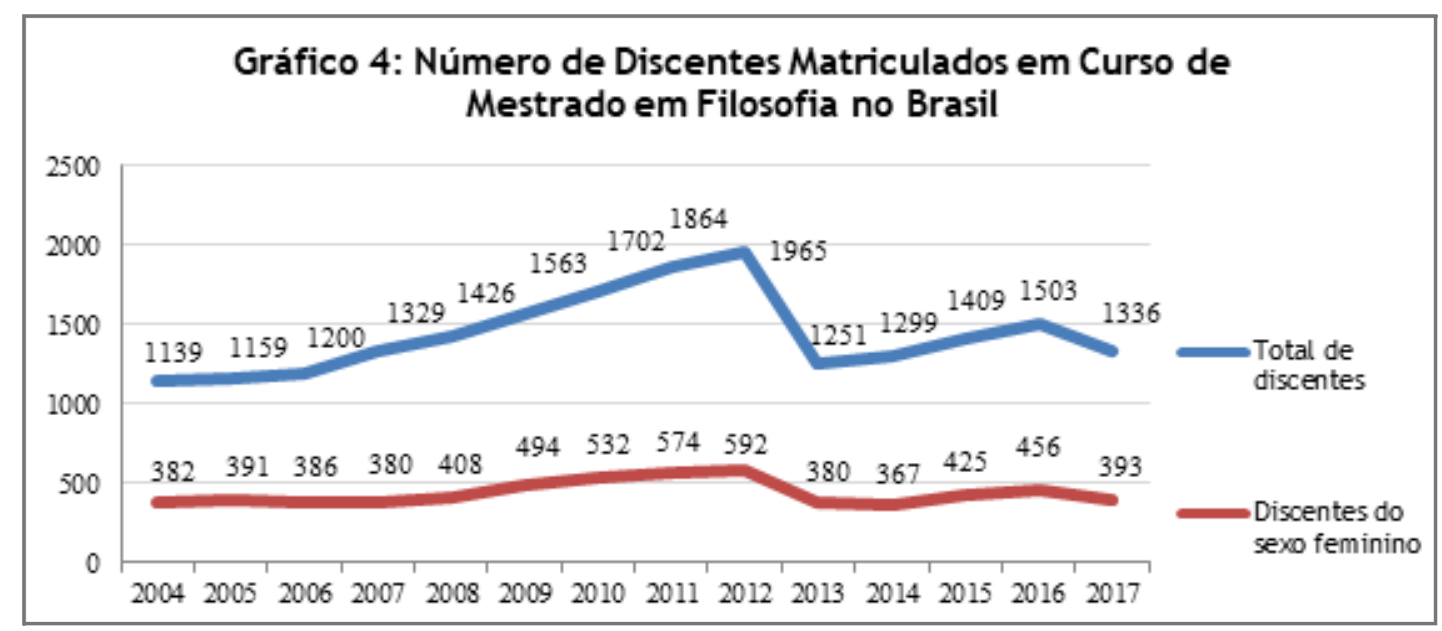

Se passamos agora para a proporção entre o número total de discentes e o número de discentes do sexo feminino, vemos, em primeiro lugar, uma queda de $5 \%$ na média da proporção de mulheres quando comparamos discentes de graduação com discentes de mestrado. Em nenhum momento a média de mulheres entre os discentes de mestrado equivale à média de mulheres entre os discentes de graduação, o que indica uma defasagem sistêmica. Não é o propósito deste trabalho especular sobre essas razões, limito-me aqui a indicar que um futuro estudo sobre as causas dessa desigualdade deve buscar as razões pelas quais tantas mulheres abandonam a carreira acadêmica no momento de ingresso na pós-graduação.

Voltemo-nos agora aos números do mestrado. Aqui se nota que a variação em torno da média de $30,6 \%$ chega a mais de 3 pontos acima da média, embora nunca chegue a 2 pontos abaixo da média. Essa variação indica que os números mais altos ocorrem mais raramente, e que números abaixo da média são mais frequentes. Também significativo nessa variação é o fato de que os números mais altos concentram-se no primeiro triênio da série (2004-2006). Como esse patamar mais alto não se repete mais, é possível identificar uma tendência de queda nos números: por exemplo, enquanto na primeira metade da série (sete primeiros anos) a média era de $31,35 \%$, na segunda metade da série essa média passa para $29,85 \%$.

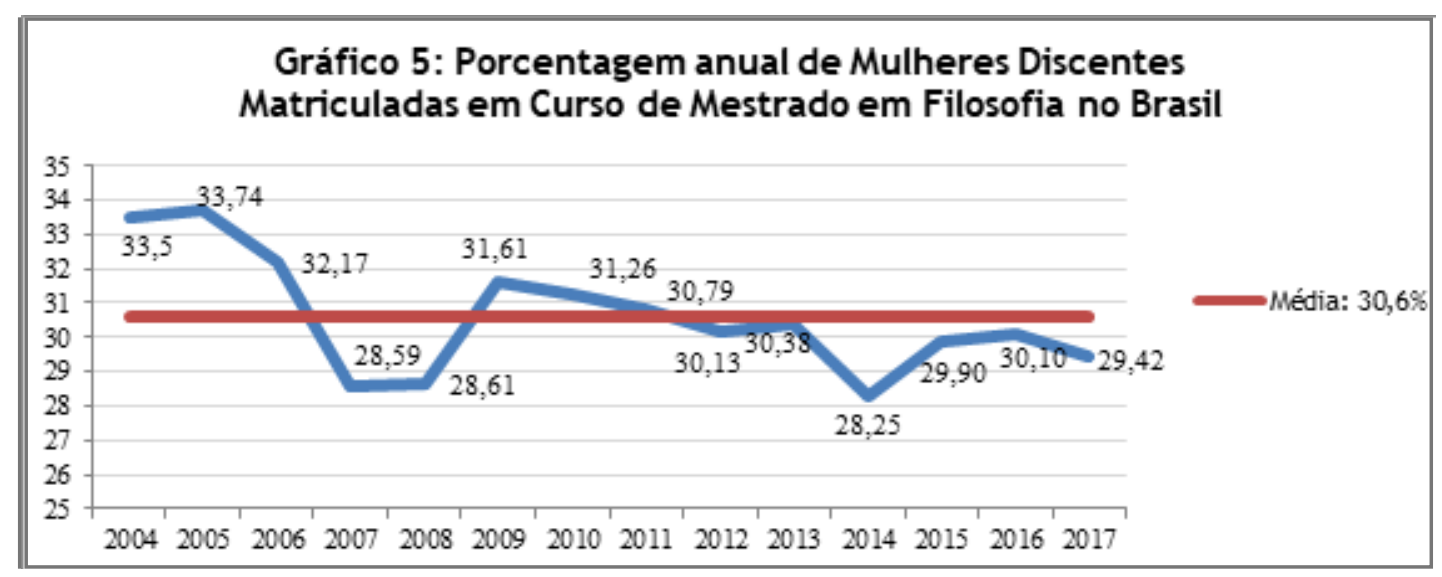


Analisando os números de cada PPG, nota-se uma grande desigualdade entre eles em termos de proporção de mestrandas. A tabela abaixo apresenta a média dessa proporção ao longo dos 14 anos em cada PPG. Embora 14 dos 47 PPGs se situem a 2 pontos abaixo ou acima da média, há uma variação de mais de 32 pontos percentuais entre o índice mais baixo e o mais alto. Isso indica que os casos nos dois extremos da classificação são particularmente diferenciados em relação à média e que seria interessante identificar as razões dessa diferenciação. Digno de nota nesse cenário é o fato de que o mestrado da UECE, terceiro curso com maior proporção de mulheres, foi fechado em 2016. Outra indicação relevante é que não parece haver qualquer relação entre número de discentes mulheres e instituições eclesiásticas, uma vez que essas últimas aparecem tanto no quartil superior (PUC-Rio e PUC-PR), quanto no inferior (PUC-RS, FSB, FAJE).

Tabela 2: Percentual de Mulheres Discentes Matriculadas em Cursos de Mestrado em Filosofia no Brasil por PPG - Média 2004-2017 - Média geral: 30,6\%

\begin{tabular}{|l|c|l|c|l|l|l|l|}
\hline \multicolumn{2}{|c|}{ Quartil Superior } & \multicolumn{2}{c|}{ Quartil Médio 1} & \multicolumn{2}{c|}{ Quartil Médio 2 } & \multicolumn{2}{c|}{ Quartil Inferior } \\
\hline UCS & 46,27 & UFPR & 33,35 & UFG & 29,14 & UFRRJ & 25,11 \\
\hline UECE & 41,95 & UFU & 32,90 & UEL & 29,06 & UFJF & 25,00 \\
\hline UFF & 37,62 & UFSCAR & 32,71 & UFSC & 29,05 & UFMT & 24,68 \\
\hline PUC-RIO & 36,99 & UFRGS & 32,44 & UNIFESP & 29,01 & UNB & 24,50 \\
\hline UGF & 35,57 & UEM & 32,39 & UFPB/J.P. & 28,59 & UNICAMP & 24,35 \\
\hline PUC/PR & 35,43 & UFPEL & 31,38 & USP & 28,04 & FSB & 22,68 \\
\hline UFBA & 35,01 & UFES & 30,89 & UFPE & 27,83 & PUC/RS & 22,67 \\
\hline UFOP & 34,71 & UFRJ/PPGLM & 30,61 & UFRJ/PPGF & 27,68 & FUFPI & 20,11 \\
\hline USJT & 34,34 & UFMG & 30,54 & PUC/SP & 26,63 & FAJE & 19,87 \\
\hline UNESP/MAR & 33,95 & UFSM & 30,44 & UFRN & 26,40 & UFABC & 17,75 \\
\hline UNB/MET & 33,74 & UNISINOS & 29,95 & UFC & 25,42 & FUFSE & 14,12 \\
\hline UERJ & 33,51 & UNIOESTE & 29,82 & UFPA & 25,38 & & \\
\hline
\end{tabular}

Passemos agora a examinar a relação entre a qualidade dos PPGs, a nota recebida pela avaliação da CAPES, e sua influência na proporção de mulheres discentes. O gráfico abaixo apresenta os coeficientes da tabela acima organizados segundo a média da sua nota de avaliação junto à Capes ao longo dos 14 anos. Ao que se constata, não é possível estabelecer qualquer padrão de relação entre a porcentagem de discentes matriculados do sexo feminino e a nota de avaliação de um PPG: a maior concentração de programas na nota média 3 também inclui os mais altos e mais baixos percentuais; ao passo que os dois únicos programas com média 7 mantêm-se nos quartis médios. 


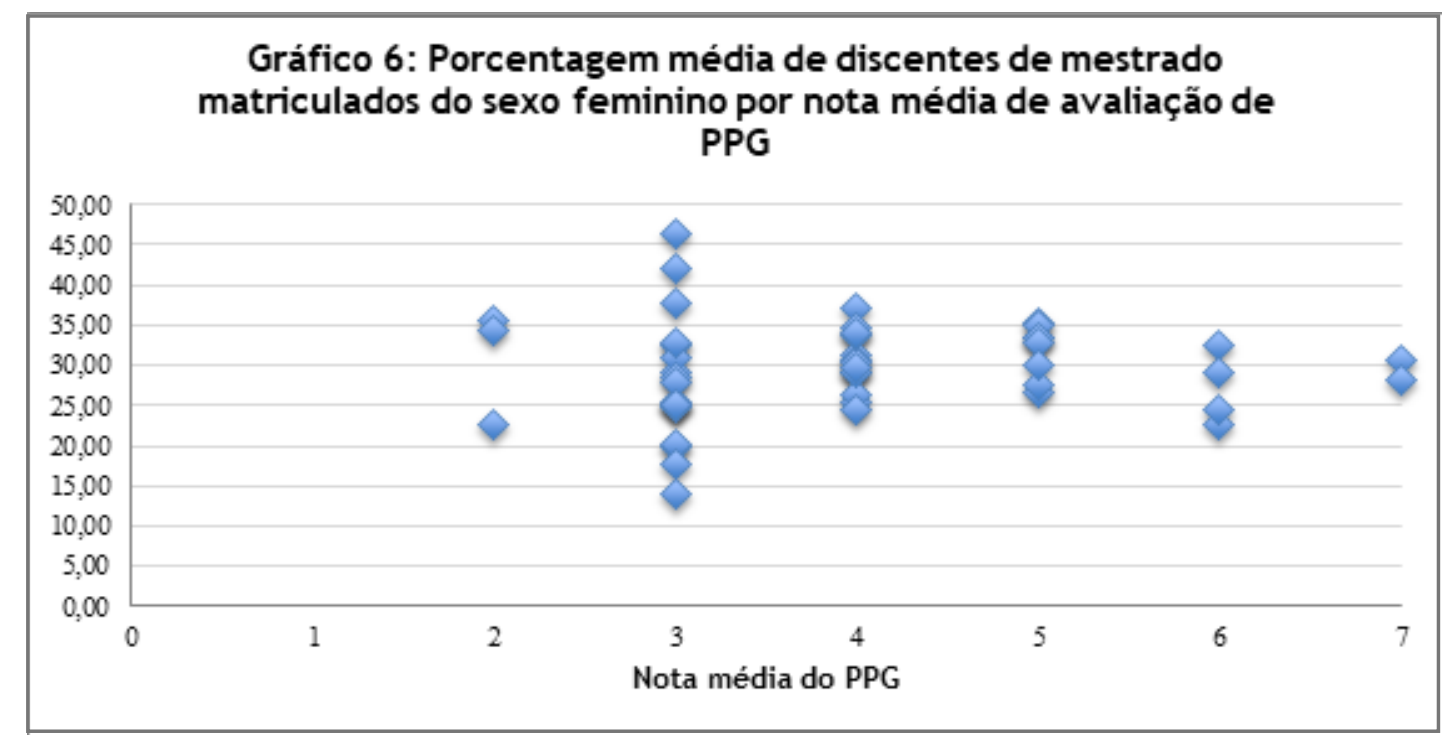

Se passamos agora à localização do PPG, vemos que também não é possível detectar uma relação direta entre a região geográfica do país em que ele se situa e um maior percentual de discentes de mestrado do sexo feminino, como mostra o gráfico abaixo.

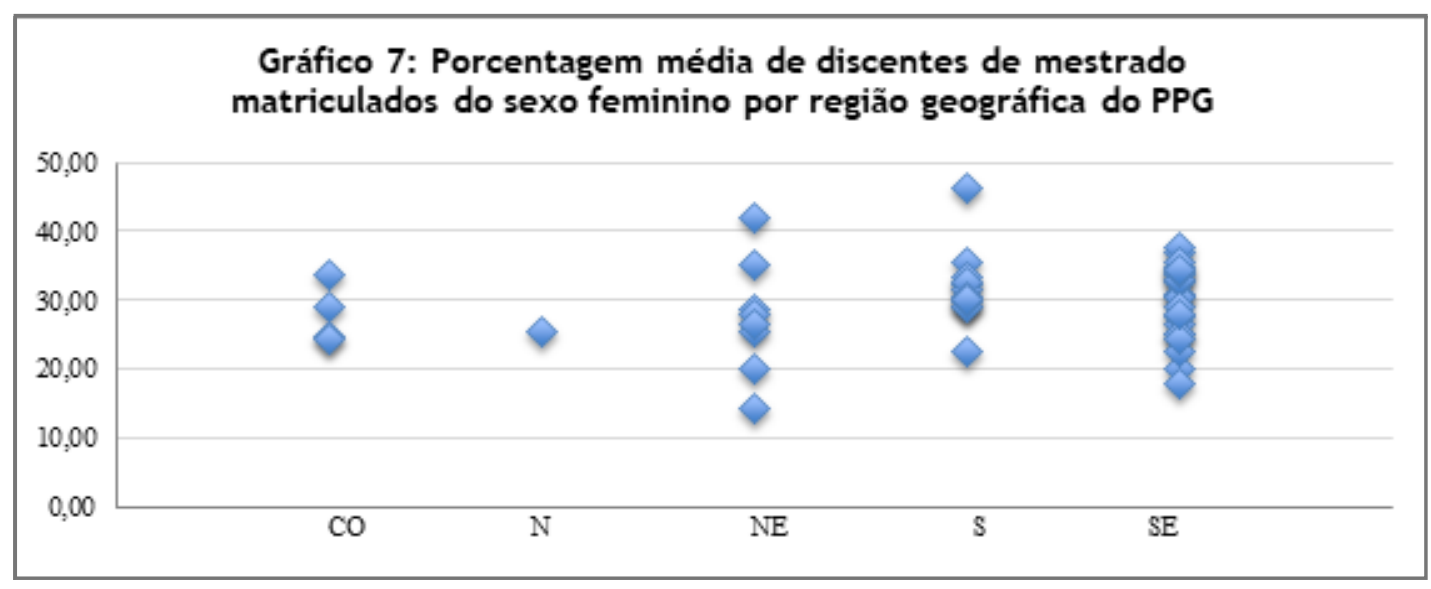

\section{Discentes de doutorado}

O número de matrículas nos cursos de doutorado no Brasil manteve tendência de crescimento até 2016, chegando a quase triplicar o número de matrículas de 2004. A tendência é interrompida em 2017, quando ele apresenta queda de 13,5\%. Esse fenômeno se explica pelo Evento 2013, uma vez que em 2017 ocorre a conclusão de curso dos alunos matriculados em 2013. Um resultado interessante do Evento 2013 é que singularmente em 2015 os números de matriculados no mestrado (1409) e no doutorado (1406) praticamente coincidem, com os números do mestrado avançando em maior grau daí em diante. Nos 14 anos, o número de discentes do sexo feminino 
acompanha tanto a alta quanto a queda do número total de matriculados, embora, como veremos adiante, não na mesma proporção.

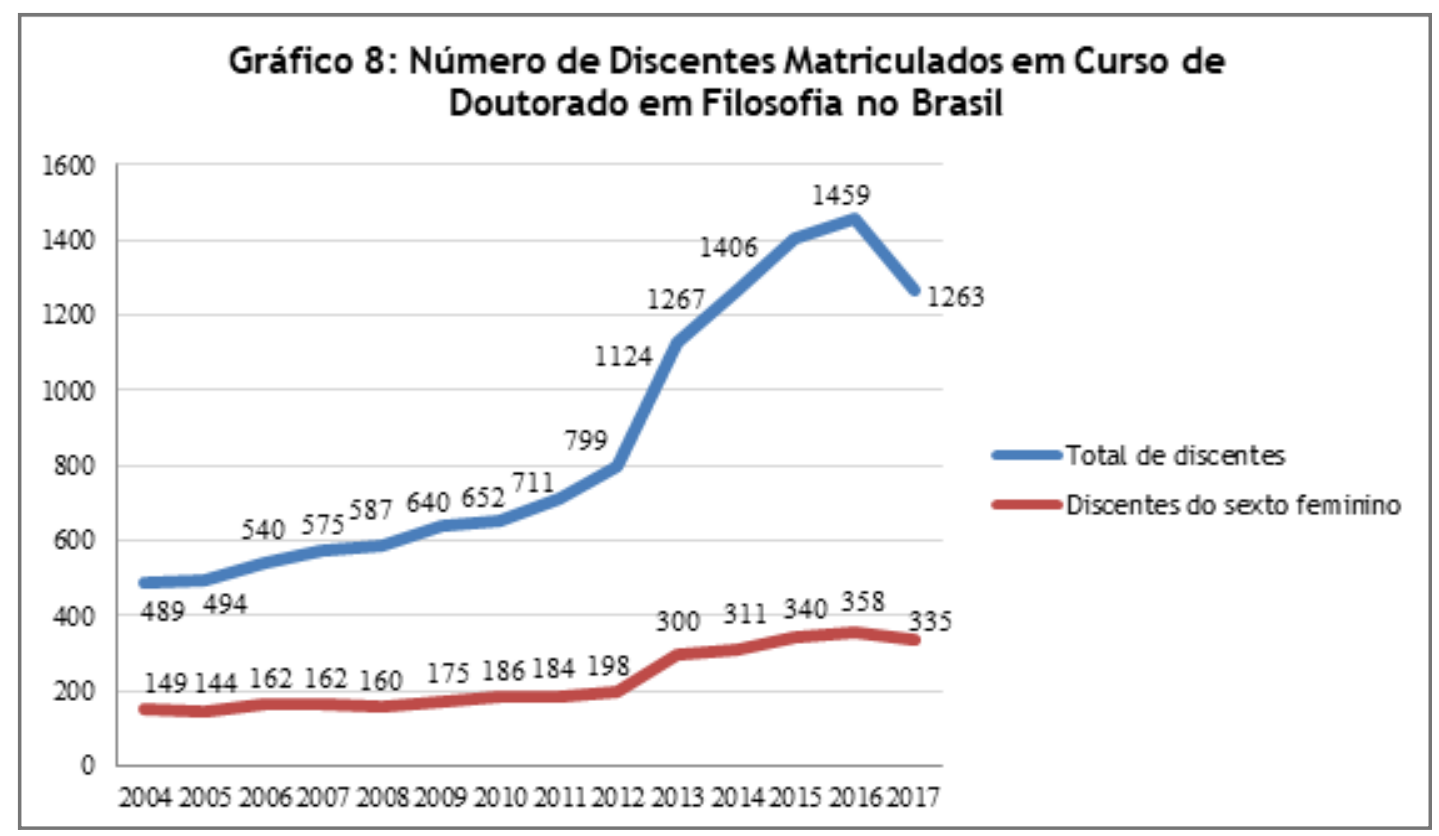

Se nos voltamos agora à proporção de mulheres no doutorado, vemos que, em oposição à média de $30,6 \%$ de discentes mulheres no mestrado ao longo dos 14 anos, a média de discentes do sexo feminino nos cursos de doutorado em filosofia é mais baixa: $26,98 \%$, indicando uma outra queda média sistemática, dessa vez de 3,5\%. Apenas no ano de 2007 a proporção de mulheres se aproxima nos dois cursos: $28,59 \%$ no mestrado e $28,17 \%$ no doutorado. Em todos os outros anos evidencia-se uma situação de defasagem sistêmica. A variação do índice em torno da média segue o padrão do mestrado com um pouco mais de amplitude: chega a 3,5 pontos acima da média e a 2,8 pontos abaixo. Mais uma vez isso expressa que os casos de alta são mais raros de que os de baixa. Ademais, a média de presença de mulheres é mais alta na primeira metade da série $(28,7 \%)$, quando comparada à segunda metade $(25,26 \%)$, indicando uma tendência de queda ao longo da série histórica também no doutorado.

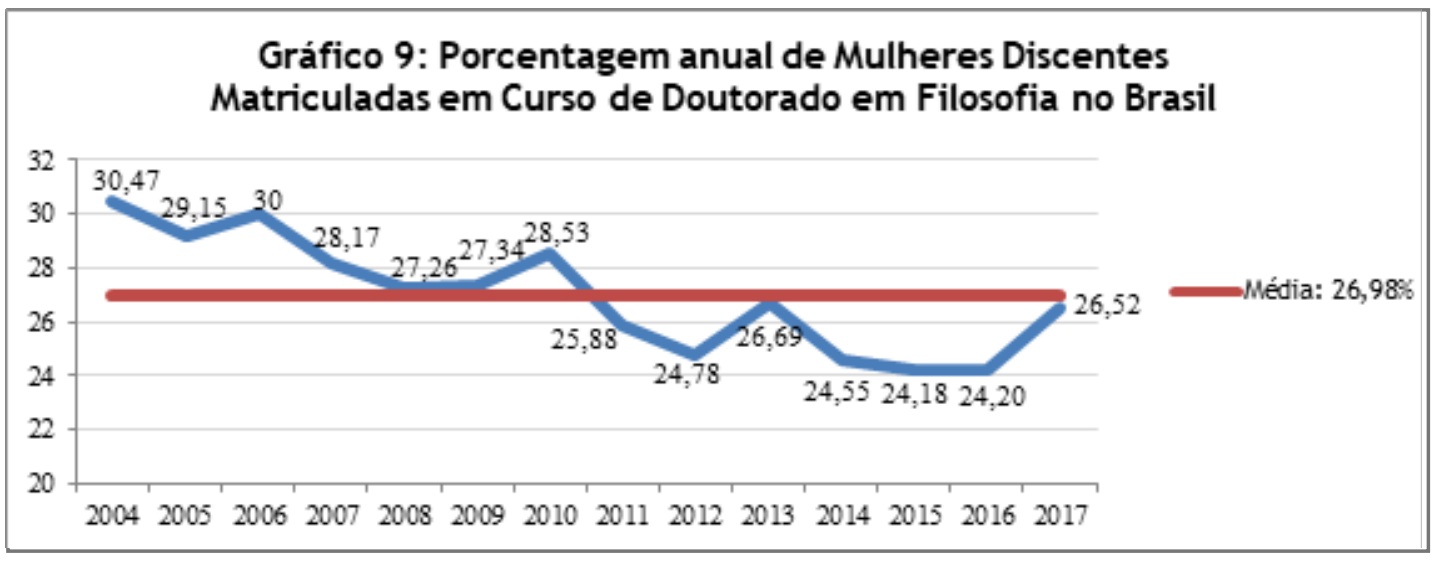


A análise da média da proporção de doutorandas em cada PPG ao longo do período indica também uma grande variação, chegando a mais de 30 pontos percentuais entre programas com maior e menor proporção de discentes mulheres.

\begin{tabular}{|c|c|c|c|c|c|c|c|}
\hline \multicolumn{8}{|c|}{$\begin{array}{c}\text { Tabela 3: Percentual de Mulheres Discentes Matriculadas } \\
\text { em Cursos de Doutorado em Filosofia por PPG } \\
\text { Média 2004-2017 - Média geral: } 26,98 \%\end{array}$} \\
\hline \multicolumn{2}{|c|}{ Quartil superior } & \multicolumn{2}{|c|}{ Quartil médio 1} & \multicolumn{2}{|c|}{ Quartil médio 2} & \multicolumn{2}{|c|}{ Quartil inferior } \\
\hline UNB & 45,45 & UFRN & 32,64 & UFSM & 25,17 & UFPEL & 19,17 \\
\hline PUC-RIO & 40,10 & USP & 32,41 & PUC/PR & 24,03 & PUC/RS & 18,76 \\
\hline UNIOESTE & 39,23 & UFSCAR & 31,44 & UNISINOS & 22,53 & UFRJ/PPGLM & 15,68 \\
\hline UERJ & 33,82 & UFRGS & 30,50 & UFPE-UFPB-UFRN & 21,18 & UFG & 15,52 \\
\hline UGF & 33,53 & UFMG & 30,16 & UFSC & 20,74 & UFPR & 12,69 \\
\hline UNIFESP & 33,04 & UFRJ/PPGF & 29,62 & PUC/SP & 19,82 & UFC & 11,20 \\
\hline & & UFBA & 25,20 & UNICAMP & 19,48 & & \\
\hline
\end{tabular}

Quando analisamos a relação entre a presença de discentes mulheres e a nota média do programa ao longo desses 14 anos, nenhum padrão é identificável. A grande concentração dos programas nas notas 4 e 5 coincide com o amplo espectro de proporção de mulheres, do índice mais baixo ao mais alto. Talvez um único detalhe digno de nota seja a localização dos dois únicos programas de média 7 no quartil médio superior.

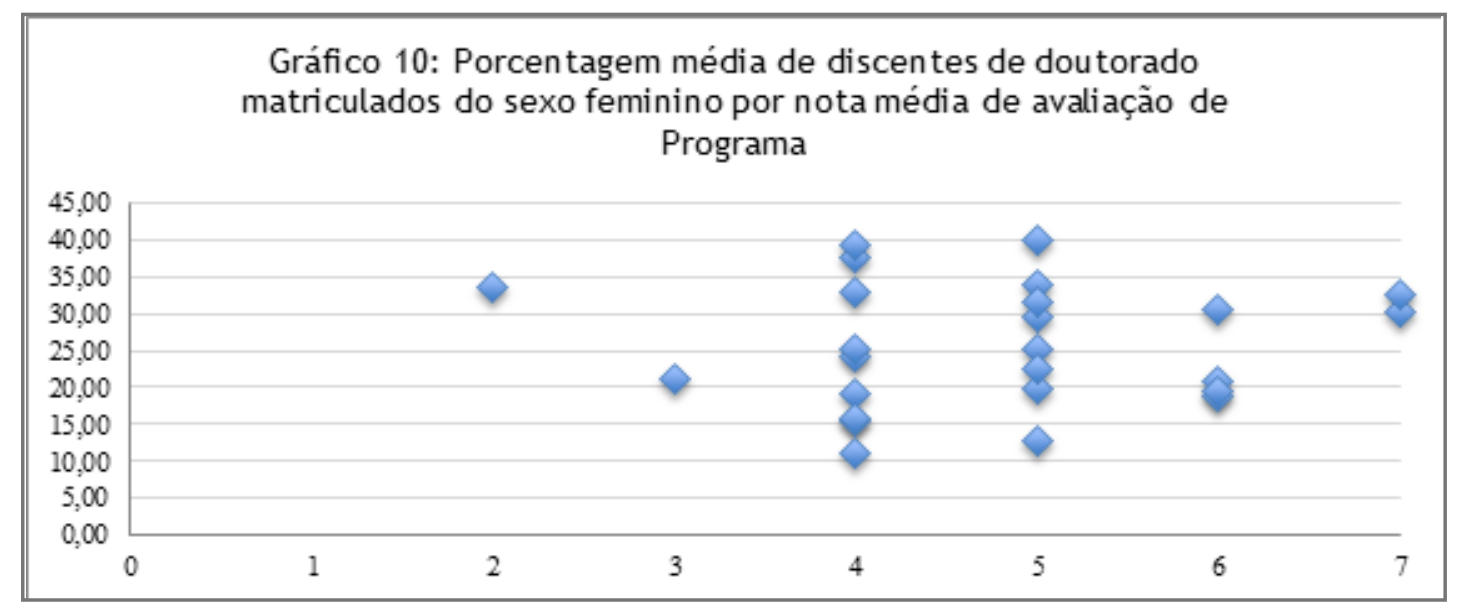

Também não é possível verificar qualquer padrão na relação entre percentual de doutorandas e região geográfica do país em que se localiza o programa. A região nordeste, por exemplo, apresenta tanto o coeficiente mais alto, quanto o mais baixo. 


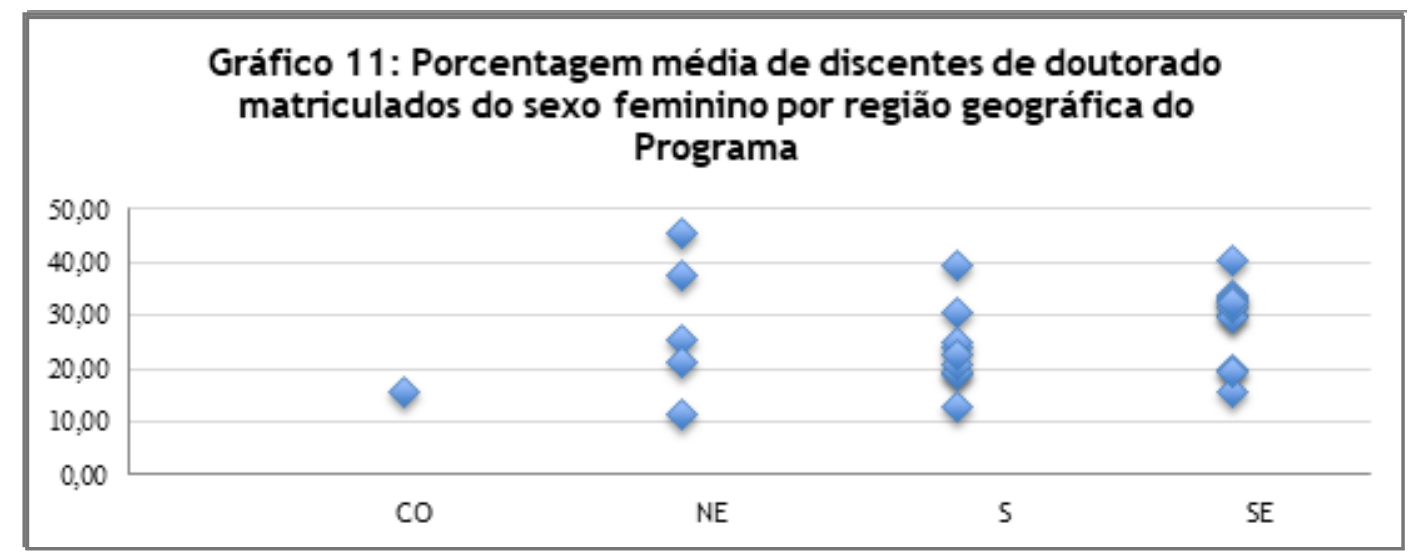

\section{Docentes permanentes}

Passando agora para o corpo permanente de professores, é visível o seu crescimento numérico, que multiplicou o número de 2004 em 2,5 vezes. A taxa de crescimento do número de docentes do sexo feminino não cresceu no mesmo ritmo, aumentando 2,2 vezes.

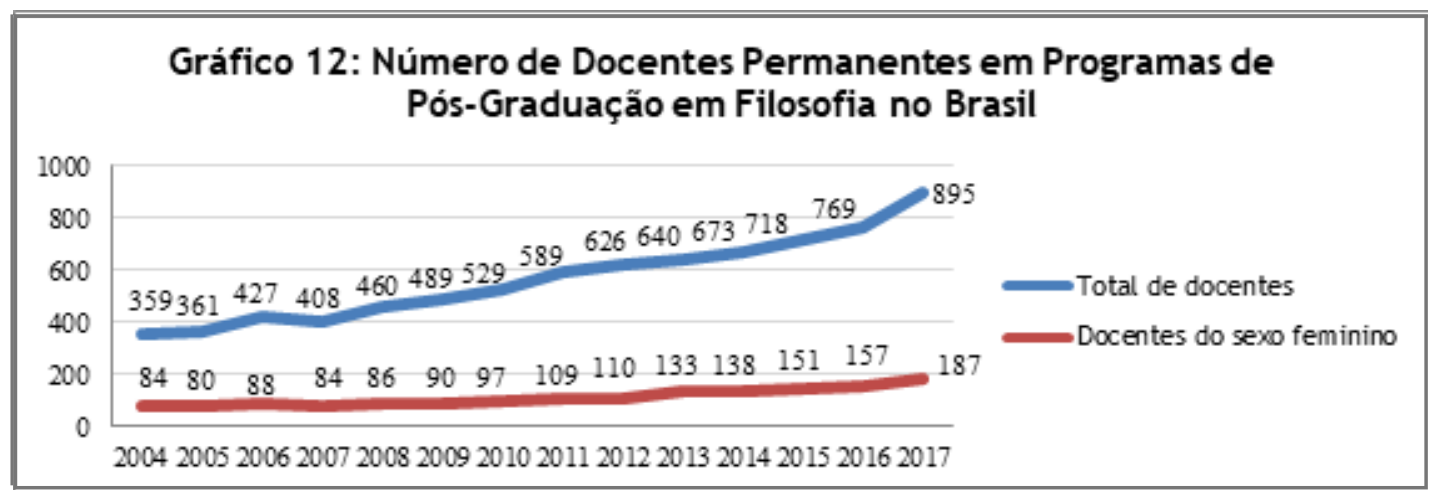

A proporção de docentes permanentes do sexo feminino em PPGs de Filosofia tem média de $20,14 \%$ ao longo dos 14 anos, o que é mais de 10 pontos abaixo da proporção de mestrandas, e quase 7 pontos abaixo da proporção de doutorandas. Nunca a média de docentes mulheres se aproxima da de doutorandas, o que também evidencia que a defasagem é sistêmica. Vê-se também no caso dos docentes o mesmo padrão de variação em torno da média: chega a 3,4 pontos acima e a 2,5 pontos abaixo, além de apresentar os maiores números no primeiro triênio (2004-2006). Com isso, evidencia-se uma tendência de queda ao longo da série histórica também entre os docentes. Porém, no caso dos docentes, há um detalhe: a proporção cai bruscamente entre os anos de 2009-2013, encontrando recuperação parcial a partir de 2014, sem, no entanto, se aproximar do patamar do primeiro triênio. 


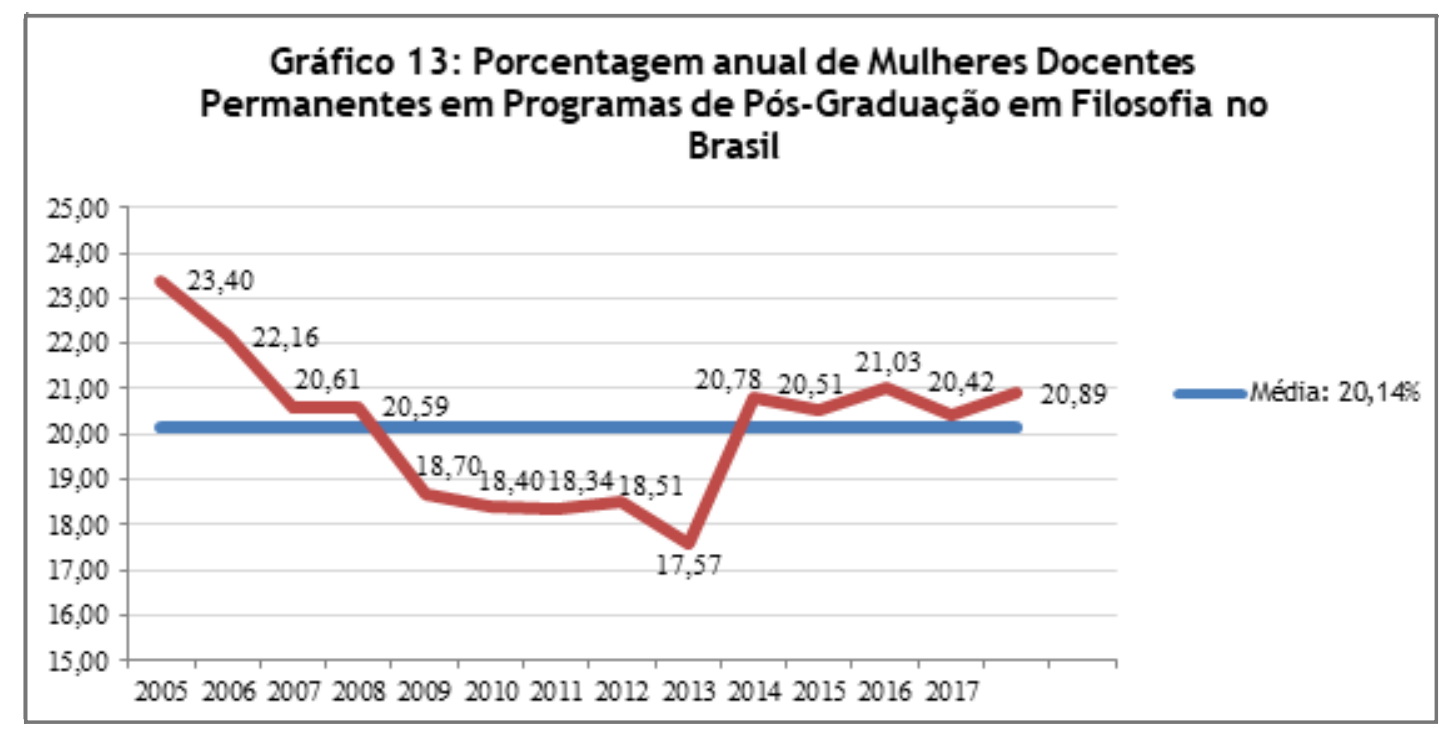

Quando analisamos os números de cada um dos programas, o contraste é grande. 0 fato de que alguns programas tenham média zero faz com que o quartil inferior tenha discrepância muito grande em relação aos demais e, consequentemente, que a diferença entre os números mais altos e os mais baixos coincida com o valor da proporção máxima, $41,28 \%$. É de se notar que a UFT e a UNIMONTES abriram seus cursos em 2017 sem nenhum professor permanente do sexo feminino em seus quadros, nesse caso a sua média reflete apenas um ano de funcionamento. Porém o caso da PUC/RS é de um extremo limite, já que a instituição não teve nenhuma professora permanente ao longo dos 14 anos.

\begin{tabular}{|l|r|l|l|l|l|l|l|r|}
\hline \multicolumn{7}{|c|}{$\begin{array}{l}\text { Média 2004-2017 - Média: } 20,14 \% \\
\text { Quala 4: Percentual de Mulheres Docentes Permanentes por PPG - }\end{array}$} \\
\hline \multicolumn{2}{|c|}{ Quartil Superior } & \multicolumn{2}{c|}{ Quartil Médio 1 } & \multicolumn{2}{c|}{ Quartil Médio 2 } & \multicolumn{2}{c|}{ Quartil Inferior } \\
\hline UFABC & 41,28 & UFRJ/PPGLM & 29,22 & UFRJ/PPGF & 17,68 & UFPE-UFPB-UFRN & 7,62 \\
\hline UFG & 40,96 & UECE & 27,19 & UGF & 17,44 & UCS & 7,17 \\
\hline UERJ & 39,99 & UFRGS & 25,71 & UNICAMP & 16,67 & UFF & 6,40 \\
\hline UFSCAR & 39,37 & UNESP/MAR & 24,59 & UERN & 16,67 & UNIOESTE & 6,09 \\
\hline UFOP & 39,16 & UNIFESP & 22,60 & UFMS & 16,67 & UNB & 5,99 \\
\hline PUC/SP & 37,48 & FUFPI & 21,28 & USP & 14,70 & UNB/MET & 5,56 \\
\hline PUC-RIO & 35,26 & UFPR & 20,34 & UFPB/J.P. & 13,60 & FAJE & 5,14 \\
\hline UFBA & 35,08 & UFPA & 20,00 & UFES & 13,34 & FSB & 4,72 \\
\hline USJT & 33,63 & UNISINOS & 18,88 & UFC & 11,64 & PUC/PR & 4,17 \\
\hline UFAM & 33,33 & UFMT & 18,33 & UFPEL & 11,60 & FUFSE & 3,75 \\
\hline UNESPAR & 33,33 & UFMA & 18,18 & UFCG & 11,11 & UFSM & 2,99 \\
\hline UFRN & 32,85 & UEL & 18,12 & UFU & 11,05 & UFPE & 1,21 \\
\hline UFMG & 31,18 & UEM & 17,98 & UFRRJ & 9,29 & PUC/RS & 0,00 \\
\hline CEFET/RJ & 29,85 & UFSC & 17,81 & UFJF & 9,09 & UFT & 0,00 \\
\hline & & & & & & UNIMONTES & 0,00 \\
\hline
\end{tabular}


A nota média de avaliação do Programa não parece ter relação direta com a porcentagem de docentes do sexo feminino. Os casos extremos, sem nenhuma docente, estão tanto na nota 3 quanto na nota 6. A maior concentração de programas, nas notas 3 e 4, apresenta também o espectro completo da proporção.

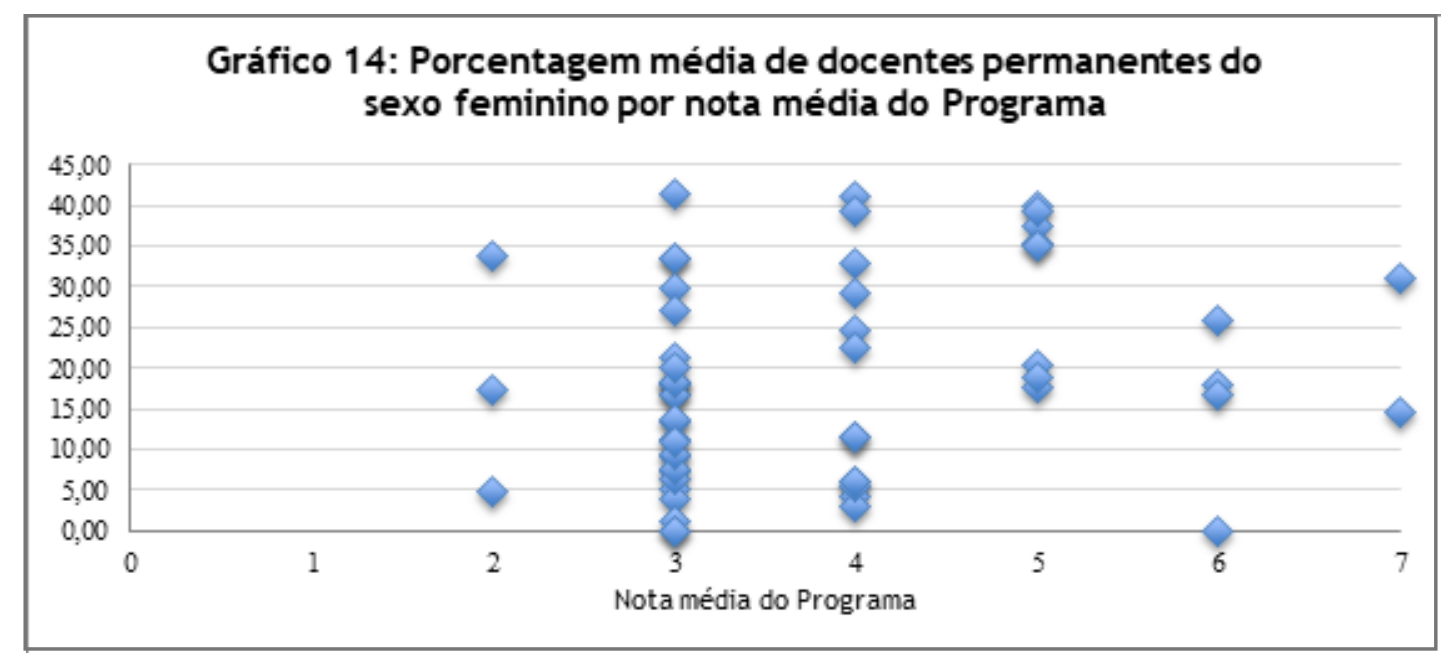

Se verificamos a relação entre docentes mulheres e a região geográfica do Programa, não há um padrão identificável, embora se note que as médias mais baixas se encontram nas regiões Nordeste e Sul.

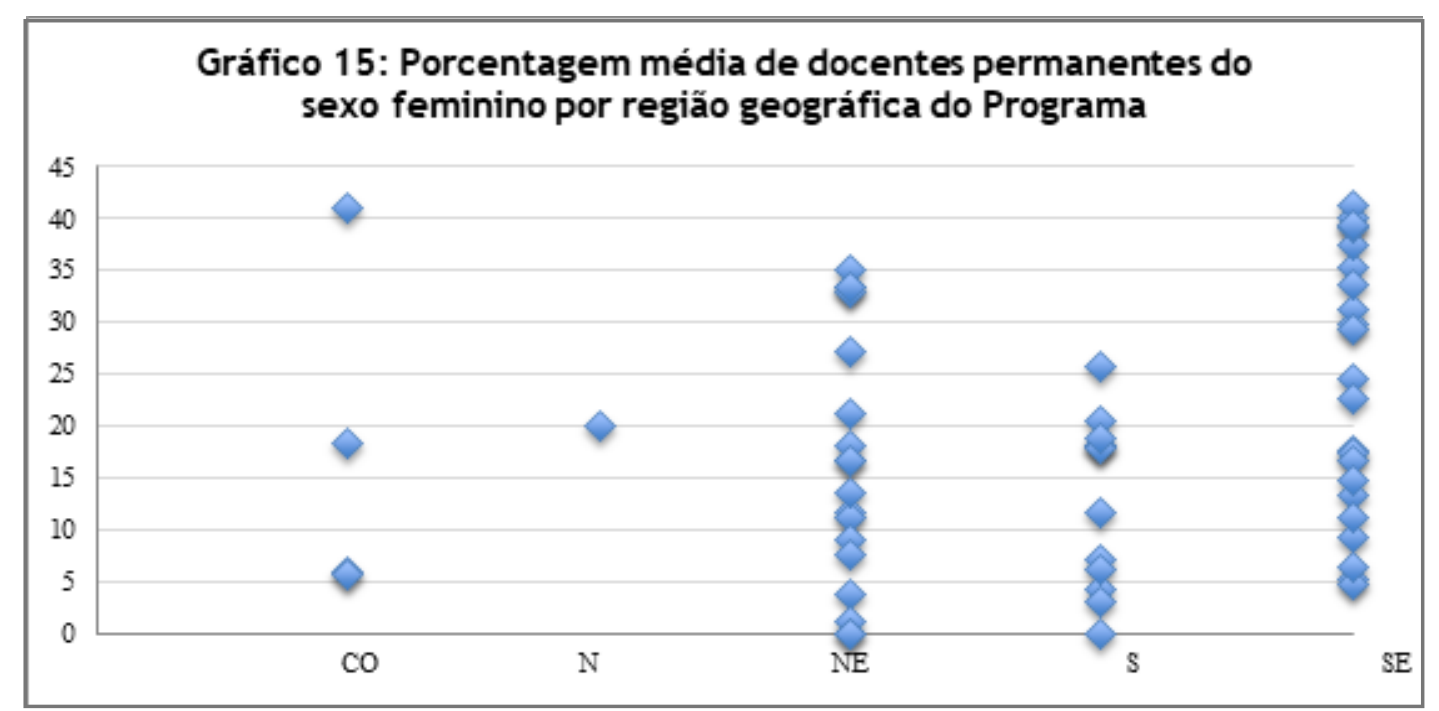

Verifica-se assim que a proporção de mulheres discentes e docentes na Pós-Graduação em Filosofia não é alterada em função da qualidade do PPG ou da sua localização. Por isso, uma vez que a variação em torno da média é muito ampla na comparação entre cada PPG, há indicativo de que a razão de uma maior ou menor presença de mulheres deve ser encontrada no ambiente de cada PPG. Essa tese ganha reforço com a verificação de que as duas etapas de maior redução na proporção de mulheres são 
no ingresso nos Programas, tanto como discentes de mestrado quanto como docentes. Em sendo assim, o ambiente de cada PPG é fator decisivo na produção tanto da igualdade quanto da desigualdade de gênero na carreira acadêmica em Filosofia, e políticas de promoção de igualdade devem tê-los como agentes prioritários.

\section{A trajetória na carreira}

Como indicado acima, na comparação entre os quatro estágios da carreira há uma diminuição sistêmica nas médias das proporções de mulheres que pode ser visualizada no gráfico a seguir, que apresenta o desenho conhecido como "leaking pipeline" ou "tubulação com vazamento", i.e., a gradual diminuição da porcentagem de um fator com simultâneo aumento de sua contraparte.

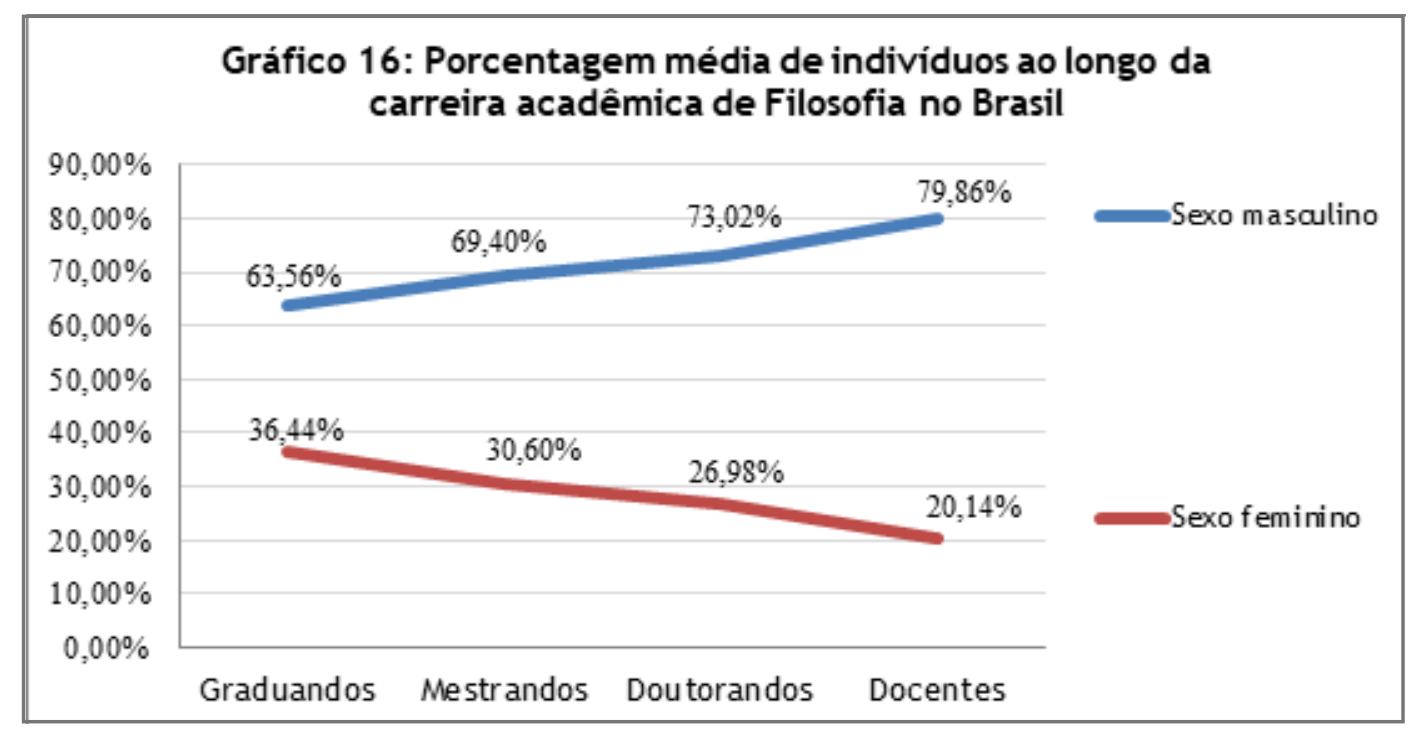

Se tomamos como base as médias de cada uma das etapas da carreira acadêmica, verifica-se que as mulheres, que saem de $36,44 \%$ dos graduandos, têm uma oportunidade de chegar ao topo da carreira, os $20,14 \%$ de docentes de pósgraduação, de 20,1/36,4, ou seja, um coeficiente de 0,55 . Já os homens têm uma oportunidade indicada pela fração 79,9/63,6, ou seja, um coeficiente de 1,26. A relação indica que, em média, os homens têm chances 2,3 vezes maior do que as mulheres, ou ainda, que as mulheres tiveram $43,6 \%$ da chance de sucesso dos homens. Os homens tiveram ao longo dos 14 anos mais do que o dobro da oportunidade das mulheres.

Todavia as médias dos 14 anos não nos permitem ver uma tendência histórica do problema. Essa tendência pode ser mostrada a partir da análise de casos. Nessa análise, seguimos dois indivíduos imaginários, um do sexo masculino e um do sexo feminino, que ingressaram na graduação em Filosofia e tiveram uma trajetória de 
sucesso, cumprindo uma sequência contínua segundo os prazos ideais: 4 anos de graduação, 2 anos de mestrado, 4 anos de doutorado e imediato ingresso como docente de pós-graduação. Os números de que dispomos nos permitem comparar dois casos, os de ingressantes em 2005 e os de ingressantes em 2008. Esses filósofos imaginários confrontar-se-ão a cada etapa de sua carreira com os números indicados anteriormente neste artigo. Eis a trajetória de uma mulher e um homem que começaram a graduação em 2005:

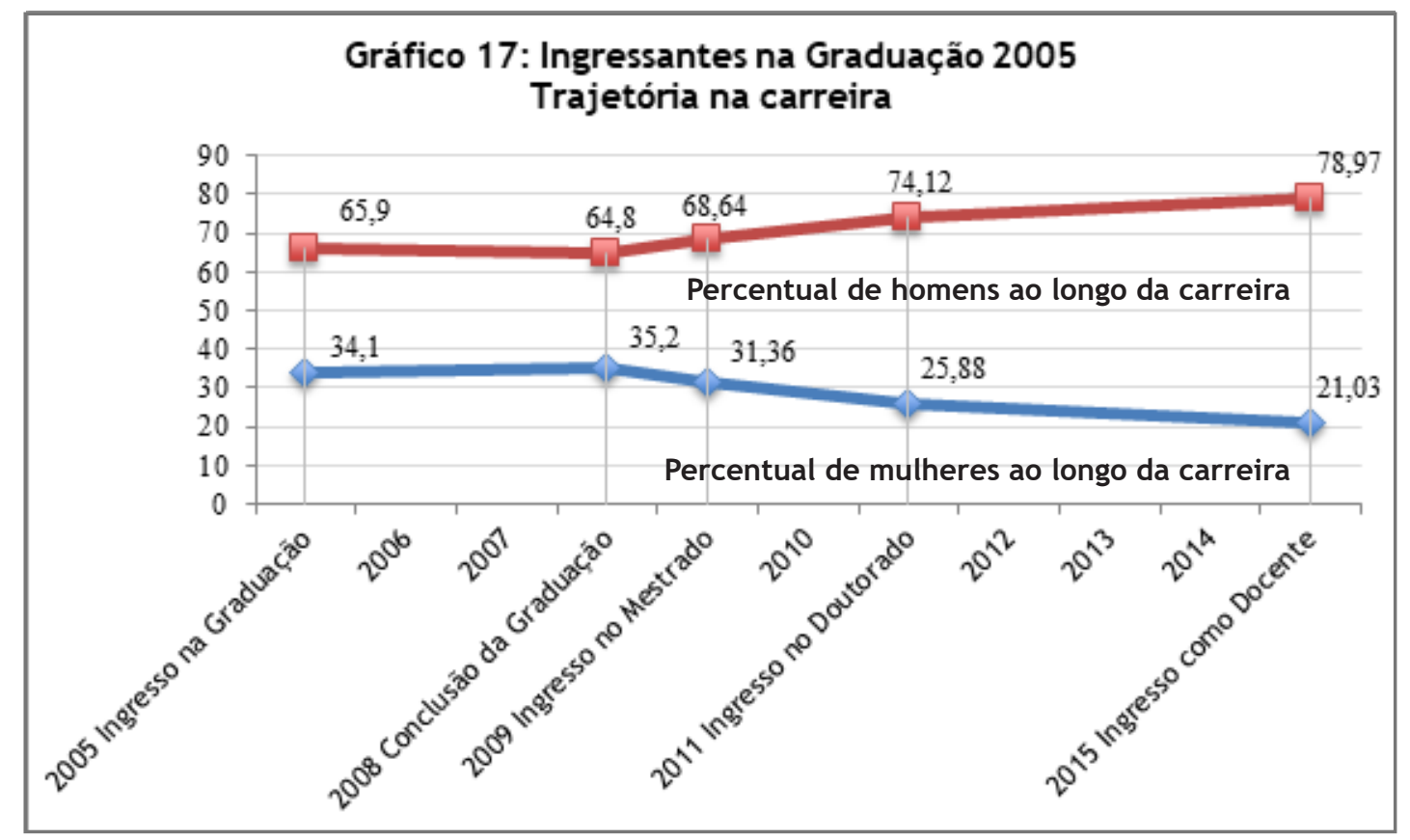

Se comparamos a base e o topo da carreira daqueles que ingressaram na graduação em 2005, vemos as mulheres têm uma chance $21 / 34(0,6)$ de conquista da posição final. Já entre os homens, a chance de conquista da posição final é de 79/66 $(1,2)$. Em se calculando a proporção de chances, temos que a chance de sucesso das mulheres é $50 \%$ da chance de sucesso dos homens. Para a geração que ingressou na graduação em filosofia em 2005, cada homem teve o dobro da oportunidade de cada mulher de chegar ao topo da carreira profissional. Isso significa que a geração de mulheres de 2015 teve uma chance acima da média de 43,6\%.

Vejamos agora a trajetória de outros dois indivíduos, um do sexo masculino e um do sexo feminino, mas que ingressaram na graduação em 2018: 


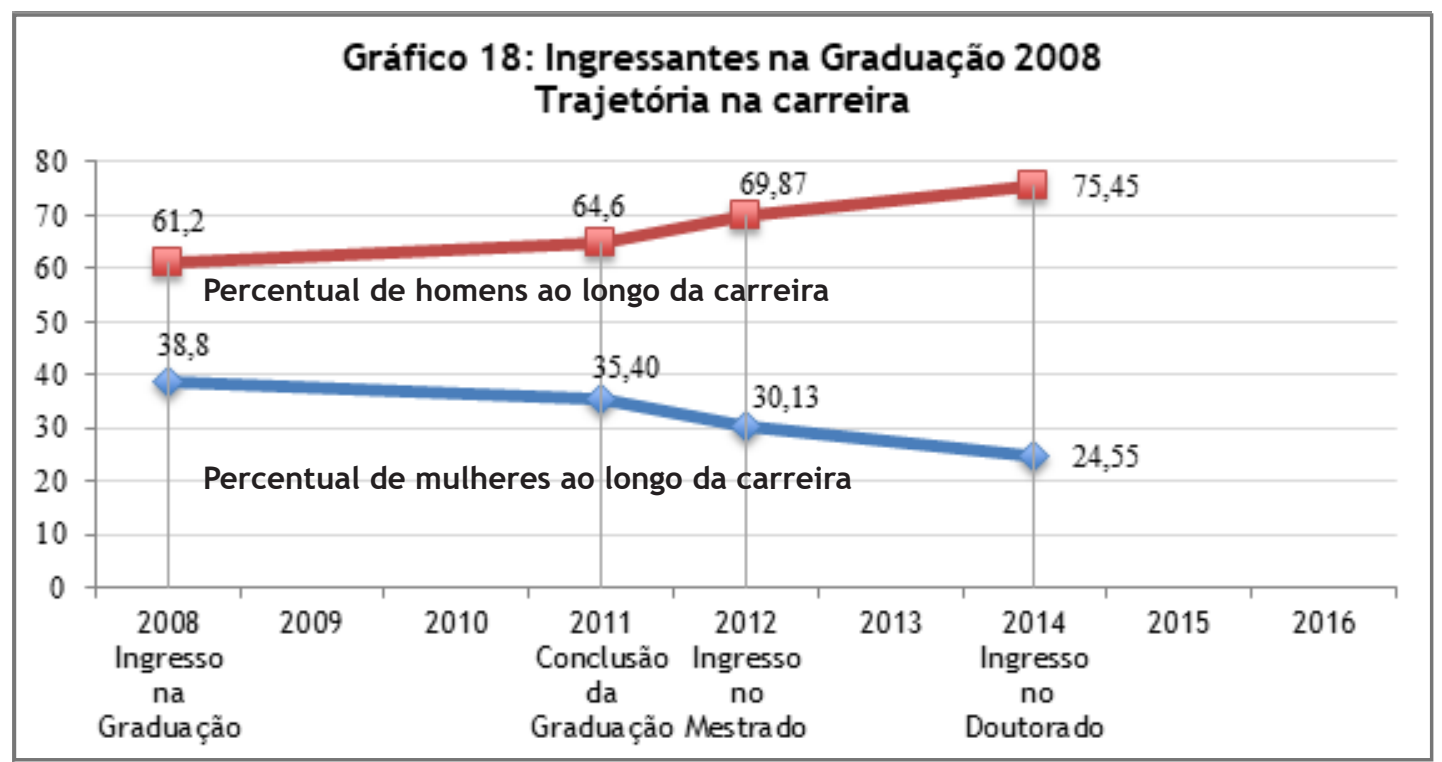

Ainda não podemos, por falta de dados, comparar a situação dos ingressantes na graduação em 2008 com o topo da carreira, porém vemos que até o ingresso no doutorado as mulheres têm uma chance de 24,5/38,8 $(0,6)$. Já entre os homens, a chance é de 75,5/61,2 (1,2). Em se calculando a proporção de chances, temos que agora, em uma etapa anterior ao topo da carreira, a chance de sucesso das mulheres é $50 \%$ menor que chance de sucesso dos homens. Note-se que, para a geração ingressante na graduação em 2005, as chances para o doutorado eram de $27 / 34$ para mulheres $(0,8)$ e $73 / 66$ para homens $(1,1)$, o que dá chances $28 \%$ menores para as mulheres. Para a geração que ingressou na graduação em filosofia em 2008, é provável que cada mulher tenha ainda menos que metade da oportunidade de cada homem de chegar ao topo da carreira profissional. Se a média de docentes mulheres se mantiver em 20,14\%, as chances dos ingressantes na graduação em 2008 seriam de 20,1/38,8 $(0,5)$ para as mulheres e de 79,9/61,2 $(1,3)$ para os homens. Para essa geração, as chances das mulheres seriam de $38,5 \%$ das dos homens, o que indica que a oportunidade de cada uma das mulheres dessa geração por ser 2,6 vezes menor que a dos homens. Nesse quadro, há para a geração de 2008 piores perspectivas que para a geração de 2005. Assim, se a média da oportunidade das mulheres é 43,6\% da dos homens, ela é a média de uma série histórica que se comporta em decréscimo da oportunidade: de 50\% na geração de 2005 para uma previsão de 38,5\% para a geração de 2008 , há uma redução de $11,5 \%$ nas chances de uma geração para a seguinte.

\section{Conclusão:}

A baixa presença de mulheres na área da filosofia não é uma particularidade brasileira. Os dados que temos são quase que exclusivamente oriundos de países 
anglófonos (cf. Hutchison \& Jenkins, 2013, p. 231-259): no Reino Unido, 24\% dos professores de departamentos de Filosofia são mulheres (Beebee \& Saul, 2011, p. 8-9); na Austrália, elas são $27 \%$ das posições permanentes em filosofia em 20056 , apresentando um ligeiro decréscimo em comparação com os $28 \%$ em $1989-91$ (Goddard, 2008, p. 4). No Canadá, $21,6 \%$ dos professores titulares são mulheres, um número que contrasta com $37,69 \%$ dos professores associados, indicando que os homens têm muito mais chances de promoção (Doucet \& Beaulac, 2013, p. 2). Nos Estados Unidos, os dados de 1992 a 2003 indicam que as mulheres têm 21\% de presença na área (Norlock, 2011, p. 1), ${ }^{3}$ dando indícios de que progressos para a paridade de gênero pararam neste patamar desde a década de 1990 (cf. Alcoff, 2011, p. 8 e Schwitzgebel \& Jennings, 2017, p. 13).

Se os baixos números da área de filosofia são uma tendência mundial, eles não obstante contrastam fortemente com os números sobre o desempenho das mulheres na Universidade no Brasil. Nossa população é de maioria feminina: 51,04\% (IBGE, 2010). Dos cidadãos com 25 anos ou mais com ensino superior completo, 12,5\% são mulheres, em contraste com 9,9\% de homens (IBGE, 2012, p. 62). Ademais, as mulheres são maioria dos estudantes do ensino superior, $57 \%$, e da pós-graduação strictu sensu, $53,46 \%$ (idem, p. 97). Portanto não há no cenário nacional geral justificativa para a baixa presença de mulheres em carreiras acadêmicas.

Por outro lado, esse trabalho mostrou que, na área da filosofia, os alunos do sexo feminino são em média $36,44 \%$ do total de graduandos, $30,6 \%$ dos mestrandos e $26,98 \%$ dos doutorandos. Entre os docentes de pós-graduação, $20,14 \%$ são mulheres. Há um padrão de constante diminuição da proporção de mulheres ao longo da carreira. Em média as mulheres têm $43,6 \%$ da oportunidade dos homens, ou seja, os homens têm 2,3 vezes mais chance na carreira. Comparando a trajetória de dois casos específicos - ingressantes na graduação em 2005 e 2008 - o estudo indicou que a perspectiva de sucesso na carreira para mulheres em 2005 era de $50 \%$ da chance dos homens, e que em 2008 a expectativa é de 38,5\%. Portanto, no Brasil, os números apresentam não apenas uma enorme desigualdade, como também uma tendência de aumento dessa desigualdade ao longo dos 14 anos. Essa tendência demanda atenção dos agentes envolvidos. Em mostrando que não há relação entre qualidade dos PPGs ou localização geográfica e maior presença de mulheres, esse trabalho indicou que são os PPGs os mais importantes agentes na produção da igualdade e da desigualdade de gênero na carreira acadêmica em Filosofia, sugerindo que políticas de promoção

3 Haslanger (2013) aponta três outros números interessantes sobre os EUA: (i) que o NSF Survey of Earned Doctorates atesta que, entre 2007 e 2011, as mulheres obtiveram de 23,84\% a 31,4\% de todos os doutorados obtidos em Filosofia nos EUA, um número menor do que os das áreas de Matemática, Química e Economia; (ii) que, de acordo com o blog Leiter Reports, docentes dos 51 principais programas de pós-graduação dos EUA contabilizam 21,9\% de mulheres; (iii) o Digest of Education Statistics de 2003 aponta que apenas 16,6\% dos filósofos em empregos pós-secundários em tempo integral nos EUA eram mulheres. 
de igualdade devem ser oriundas dos Programas individualmente.

Diante dessa tarefa, pequenas medidas podem balancear esse desequilíbrio na área da Filosofia e mudar o cenário em pouco tempo. Antes de tudo, a sugestão é de que o monitoramento constante desses números seja tarefa da comunidade filosófica como um todo. Uma outra sugestão é de usar o índice do INEP de proporção de mulheres e homens na graduação como parâmetro para a distribuição de bolsas PIBIC, estimulando o ingresso de mulheres na pesquisa. Finalmente, sugere-se que a Capes, em sua avaliação de PPGs, considere a proporção entre homens e mulheres como um dos índices de avaliação no item "impacto econômico, social e cultural do PPG". Essa política institucional deveria tomar os índices sobre proporção de mulheres concluintes da graduação em Filosofia no Brasil fornecidos pelo INEP como meta para os Programas de Pós-Graduação e solicitar dos PPGs explicações sobre a desigualdade de gênero entre seus membros. 0 avaliador anônimo deste artigo objetou essa sugestão alegando que ela é "feita abruptamente e sem analisar com calma o impacto que isso teria ou mesmo a possibilidade de implantação dessa medida”. A possibilidade de implantação está dada: a ficha avaliação da Capes já tem a categoria apropriada e é evidente que a produção de desigualdade ou da igualdade de gênero é uma forma de impacto social dos PPGs. Já a preocupação do avaliador com as consequências de tal avaliação reflete seu receio de que alguns PPGs possam ser prejudicados de forma inadequada. Entendo que essa preocupação inverte a ordem das razões de uma avaliação, que deve se pautar por princípios considerados justos e não pelo prejuízo que isso pode causar a agentes em particular. Assim não há argumentos pela inadequação da avaliação. Ao contrário, ela se apresenta como ocasião propícia para que os PPGs apresentem as suas justificativas caso a caso, ao invés de apenas se silenciarem sobre o assunto. Caberia à comissão de avaliação considerar se as razões apresentadas são ou não adequadas.

\section{Referências}

Alcoff, L. (2011). A call for climate change. APA Newsletter on Feminism and Philosophy, 11(1), pp. 7-9.

Araújo, C. (2016). Mulheres na Pós-Graduação em Filosofia no Brasil - 2015. Recuperado de: $\quad$ http://anpof.org/portal/index.php/pt-BR/comunidade/communityforum-pack073a51/category-items/4-community-forum/155-mulheres-na-posgraduacao-em-filosofia-no-brasil. [acesso em: 17 de março de 2019].

Beebee, H., and Saul, J. (2011). Women in philosophy in the UK. British Philosophical Association: Society for Women in Philosophy in the UK. Recuperado de: https: / / www.bpa.ac.uk/uploads/2011/02/BPA_Report_Women_In_Philosophy.pdf [acesso em: 17 de março de 2019].

CAPES. (2013a). Coleta de Dados, Discentes dos Programas de Pós-Graduação stricto sensu no Brasil 2004 a 2012. Brasília: CAPES. Recuperado de: https:// dadosabertos.capes.gov.br/dataset/coleta-de-dados-discentes-dos-programas- 
de-pos-graduacao-stricto-sensu-no-brasil-2004-a-2012. [acesso em: 17 de março de 2019].

CAPES. (2013b). Coleta de Dados, Docentes dos Programas de Pós-Graduação stricto sensu no Brasil 2004 a 2012. Brasília: CAPES, 2017. Recuperado de: https:// dadosabertos.capes.gov.br/dataset/coleta-de-dados-docentes-dos-programasde-pos-graduacao-stricto-sensu-no-brasil-2004-a-2012. [acesso em: 17 de março de 2019].

CAPES. (2017a). Coleta de Dados, Discentes dos Programas de Pós-Graduação stricto sensu no Brasil 2013 a 2016. Brasília: CAPES. Recuperado de: https: // dadosabertos.capes.gov.br/dataset/discentes-da-pos-graduacao-stricto-sensudo-brasil. [acesso em: 17 de março de 2019].

CAPES. (2017b). Docentes da Pós-Graduação Stricto Sensu no Brasil de 2013 a 2016. Brasília: CAPES, 2017. Recuperado de: https://dadosabertos.capes.gov.br/ dataset/docentes-posgraduacao. [acesso em: 17 de março de 2019].

CAPES. (2018a). Coleta de Dados, Discentes dos Programas de Pós-Graduação stricto sensu no Brasil 2017. Brasília: CAPES. Recuperado de: https://dadosabertos. capes.gov.br/dataset/coleta-de-dados-discentes-da-pos-graduacao-strictosensu-do-brasil-2017. [acesso em: 17 de março de 2019].

CAPES. (2018b). Coleta de Dados, Docentes dos Programas de Pós-Graduação stricto sensu no Brasil 2017. Brasília: CAPES. Recuperado de: https://dadosabertos. capes.gov.br/dataset/coleta-de-dados-docentes-da-pos-graduacao-strictosensu-no-brasil-2017. [acesso em: 17 de março de 2019].

Doucet, M. \& Beaulac, G. (2013). Report on the Canadian Philosophical Association Equity Survey: historical trends. Recuperado de: https://www.acpcpa.ca/ cpages/reports. [acesso em: 17 de março de 2019].

Goddard, E. (2008). Improving the Participation of Women in the Philosophy Profession Report B: Appointments by Gender in Philosophy Programs in Australian Universities, Report to the Australasian Association of Philosophy. Recuperado de: https://aap.org.au/Resources/Documents/publications/IPWPP/ IPWPP_ReportB_Appointments.pdf [acesso em: 17 de março de 2019].

Haslanger, S. (2013). Women in Philosophy? Do the Math. The Stone, 2 setembro de 2013. Recuperado de: https://opinionator.blogs.nytimes.com/2013/09/02/ women-in-philosophy-do-the-math/ [acesso em: 17 de março de 2019].

Hutchison, K \& Jenkins, F. (2013). Women in Philosophy: what needs to change. Oxford: Oxford University Press.

IBGE. (2010). Sinopse do Censo demográfico 2010. Rio de Janeiro: IBGE. Recuperado de: https: / / www.ibge.gov.br/censo2010/apps/sinopse/index.php?dados=11\&uf=00. [acesso em: 17 de março de 2019].

IBGE. (2012). Censo demográfico 2010: educação e deslocamento, resultado da amostra. Rio de Janeiro: IBGE. Recuperado de: https://biblioteca.ibge.gov.br/ pt/biblioteca-catalogo?view=detalhes\&id=7545. [acesso em: 17 de março de 2019]

INEP. (2005). Enade 2005: Relatório Síntese Área de Filosofia. Recuperado de: Brasília: INEP. http://download.inep.gov.br/download/enade/2005/relatorios/ Filosofia.pdf [acesso em: 17 de março de 2019]. 
INEP. (2008). Enade 2008: Relatório Síntese Filosofia. Brasília: INEP. Recuperado de: http://download.inep.gov.br/educacao_superior/enade/relatorio_ sintese/2008/2008_rel_sint_filosofia.pdf [acesso em: 17 de março de 2019].

INEP. (2011). Enade 2011: Relatório Síntese Filosofia. Recuperado de: Brasília: INEP. http://download.inep.gov.br/educacao_superior/enade/relatorio_ sintese/2011/2011_rel_filosofia.pdf [acesso em: 17 de março de 2019].

INEP. (2014). Enade 2014: Relatório Síntese Filosofia. Brasília: INEP. Recuperado de: http://download.inep.gov.br/educacao_superior/enade/relatorio_ sintese/2014/2014_rel_filosofia.pdf [acesso em: 17 de março de 2019].

INEP. (2018). Enade 2017: Relatório Síntese de Área: Filosofia. Brasília: INEP. Recuperado de: http://download.inep.gov.br/educacao_superior/enade/ relatorio_sintese/2017/Filosofia.pdf [acesso em: 17 de março de 2019].

Norlock, K. (2011). Women in the Profession: A more formal report to the CSW, 2006. Recuperado de: https://docs.google.com/ 